\title{
Differential Diagnosis of Thyroid Follicular Neoplasm from Nodular Hyperplasia by Shear Wave Elastography
}

\author{
Myung Hi Yoo ${ }^{1,2, *}$, Hye Jeong Kim ${ }^{1, *}$, In Ho Choi ${ }^{3}$, Ji-Oh Mok ${ }^{4}$, Hyeong Kyu Park', Dong Won Byun ${ }^{1}$, Kyoil Suh ${ }^{1}$
}

'Division of Endocrinology and Metabolism, Department of Internal Medicine, Soonchunhyang University Seoul Hospital, Soonchunhyang University College of Medicine; ${ }^{2}$ Elim Thyroid Clinic; ${ }^{3}$ Department of Pathology, Soonchunhyang University Seoul Hospital, Soonchunhyang University College of Medicine, Seoul; ${ }^{4}$ Division of Endocrinology and Metabolism, Department of Internal Medicine, Soonchunhyang University Bucheon Hospital, Soonchunhyang University College of Medicine, Bucheon, Korea

\begin{abstract}
Objective: More than $50 \%$ of diagnostic surgery in cytologically indeterminate thyroid nodules revealed benign nodules of which nodular hyperplasia $(\mathrm{NH})$ accounted for about half. Preoperative exclusion of $\mathrm{NH}$ may decrease diagnostic surgery. We aimed to study the diagnostic performance of shear wave elastography (SWE) to differentiate follicular neoplasm (FN) from NH in follicular lesions of thyroid nodules.

Methods: We analyzed the data from 61 patients who underwent SWE before ultrasound-guided core-needle biopsy (CNB) from August 2016 to May 2018 and CNB results were $\mathrm{FN}(\mathrm{n}=19)$ and $\mathrm{NH}(\mathrm{n}=42)$. We analyzed the magnitude of elasticity index (EI) and patterns of high El area $(\mathrm{El}>36 \mathrm{kPa})$. The patterns of high El area was classified as marginal pattern (high El areas are restricted in the outer $1 / 3$ of the nodule) and traversing pattern (high El areas approaching further to the center of the nodule within inner 2/3 of the nodule).

Results: The $\mathrm{E}_{\mathrm{Max}} \mathrm{E}_{\mathrm{Mean}}, \mathrm{E}_{\mathrm{SD}}$, and percent of high $\mathrm{El}$ area were significantly lower in $\mathrm{FN}$ than $\mathrm{NH}(\mathrm{P}<0.001)$. The diagnostic performance to predict FN showed sensitivity, specificity, and accuracy of $95 \%, 90 \%$, and $92 \%$ by $\mathrm{E}_{\mathrm{Max}}<42.1 \mathrm{kPa}$, and of $95 \%, 79 \%$, and $84 \%$ by $\mathrm{E}_{\text {Mean }}<23.5 \mathrm{kPa}$, and of $89 \%, 93 \%$, and $92 \%$ by marginal pattern of high $\mathrm{El}$ area, respectively.

Conclusion: Novel diagnostic criteria of $\mathrm{E}_{\mathrm{Max}}$ less than $42.1 \mathrm{kPa}$ and marginal pattern of high El area on SWE can predict FN with high diagnostic accuracy, waiving diagnostic surgery of $\mathrm{NH}$ in indeterminate cytology.
\end{abstract}

Keywords: Elastography; Shear wave; Follicular neoplasm; Thyroid nodule

\section{INTRODUCTION}

Thyroid nodules are found up to $60 \%$ of the population on ultrasound (US) [1,2] and the incidence of thyroid cancer is reported $5 \%-15 \%$ of the nodules [3]. Fine-needle aspiration cytology (FNA) is regarded as the first diagnostic step to differentiate malignant from benign nodules. FNA has served with high accuracy to diagnose papillary thyroid carcinoma which accounts for $80 \%-90 \%$ of all thyroid cancer because papillary thyroid carcinoma has several specific cytological nuclear features, such as optically clear elongated nuclei with nuclear grooves and intranuclear cytoplasmic pseudoinclusions [4-6]. Papillary thyroid carcinoma also shows several characteristic findings in US including microcalcification, non-parallel orientation (greater in the anteroposterior dimension than the transverse dimension), irregular margin, and hypoechogenicity.

On the other hand, follicular thyroid carcinoma (FTC) has no reliable diagnostic cytologic findings on FNA [7-9] nor characteristic US findings [10,11], showing similar or overlapping features with benign follicular lesions as follicular adenoma (FA) and nodular hyperplasia (NH) both on FNA [12-14] and US. FTC is confirmed postoperatively by capsular invasion or angioinvasion [5], so preoperative distinction from FA is impossible by FNA.

Postoperative evaluation of FTC revealed preoperative FNA was
Correspondence to: Myung Hi Yoo

Division of Endocrinology and Metabolism, Department of Internal Medicine, Soonchunhyang University Seoul, Hospital, Soonchunhyang

University College of Medicine, 59 Daesagwan-ro, Yongsan-gu, Seoul 04401, Korea

Tel: +82-2-709-9190, Fax: +82-2-709-9083, E-mail: mhyoo@schmc.ac.kr, elimy0011@gmail.com

*These two authors contributed equally to this work.

Received: Apr. 3, 2019/ Accepted after revision: May 22, 2019
(C) 2019 Soonchunhyang Medical Research Institute This is an Open Access article distributed under the terms of the Creative Commons Attribution Non-Commercial License (http://creativecommons.org/licenses/by-nc/4.0/) 
classified as benign follicular lesion (category II), atypia or follicular lesion of undetermined significance (AUS/FLUS, category III), follicular neoplasm or suspicious for follicular neoplasm (FN/SFN, category IV), or suspicious for malignancy (SM, category V) according to the Bethesda System $[9,15]$. And diagnostic surgery of the thyroid nodules with FNA in category III or IV revealed malignancy rate was $20 \%-50 \%[7,8,12,13,16-20]$. Unnecessary surgery for benign nodules was reported as $50 \%-80 \%$, and about $30 \%-50 \%$ of benign surgery was revealed as $\mathrm{NH}[13,20]$.

In the aspect of clinical management, if FNA of FTC showed category III or IV by showing microfollicular patterns, FTC may be detected by diagnostic surgery. But when it showed features of macrofollicular pattern compatible with category II on FNA, it is hard to select possible candidate of FTC in large numbers of benign nodules accounting for $65 \%$ of thyroid nodules [6], while it shows no specific findings on FNA and US. And this infrequent case may make litigious episode, especially first diagnosed as benign on FNA and later clarified as malignant due to distant metastasis $[5,14,21]$.

For decades, continuous efforts have been made to preoperatively differentiate malignant follicular lesions from benign lesions, including thyroxine suppression, analysis of clinical findings [22], US findings [23], core-needle biopsy (CNB) [24], and molecular tests [25-30]. CNB may help differentiate NH from FN [31-33], but it is not always possible and practical to perform CNB for the large numbers of benign thyroid nodules. Molecular tests help select malignant follicular lesion with high sensitivity but show low specificity around 50\% [25] and may show false positive results in benign follicular lesions. Also the cost is expensive to perform as routine screening tests.

Histopathologically NH shows focal nonneoplastic hyperplasia and subsequent involutional changes accompanied by various degenerative changes including hemorrhage, infiltration of inflammatory cells, and fibrotic change with incomplete capsule formation $[4,34]$, while FA is composed of neoplastic cells surrounded by the complete capsulation and shows typically scanty amount of interstitial tissue [5] and devoid of degenerative change [35]. So the degree and quantity of fibrosis is usually larger in NH than FA.

Recent application of SWE showed it was useful in the evaluation of fibrosis, especially in the evaluation of chronic liver disease and liver cirrhosis. SWE of liver (FibroScan) which measures the degree of fibrosis in chronic liver disease has replaced CNB in the evaluation of cirrhotic change of the chronic liver disease [36]. Be- sides the SWE of liver has the advantage of noninvasiveness, it can evaluate the whole hepatic parenchyma compared with the small pieces of tissue on $\mathrm{CNB}$ which sometimes does not represent the whole hepatic parenchymal change.

We tried to evaluate whether SWE can differentiate FN from $\mathrm{NH}$ in thyroid follicular lesions so that preoperative exclusion of $\mathrm{NH}$ from diagnostic surgery might increase the rate of malignancy and avoid unnecessary thyroidectomy due to $\mathrm{NH}$.

First we tried to assess the accuracy of CNB results in thyroid follicular lesion by comparison with surgical pathology and validate the adequacy of CNB to be used as diagnostic standard, because most follicular lesions cannot be directed to surgery. Second we aim to study whether SWE can differentiate between FN and $\mathrm{NH}$ in thyroid follicular lesions, by comparing SWE with CNB or surgical pathology. We analyzed the magnitude of EI and pattern of high EI area of FN and NH to figure out the differential diagnostic criteria by SWE.

\section{MATERIALS AND METHODS}

\section{Study population}

To evaluate the accuracy of CNB to be used as diagnostic standard comparing with surgical pathology, we retrospectively reviewed the medical records of 982 consecutive patients who underwent thyroid surgery at Soonchunhyang University Hospital between January 2012 and December 2017. Among these subjects, the data from 141 patients who had surgical pathology results with $\mathrm{NH}(\mathrm{n}=77), \mathrm{FA}(\mathrm{n}=49)$, and FTC $(\mathrm{n}=15)$ were analyzed.

To address the role of SWE for the differentiation of FN and $\mathrm{NH}$, a total of 452 consecutive patients who visited the thyroid clinic at Soonchunhyang University Hospital for the evaluation of thyroid nodules from August 2016 through May 2018 were retrospectively reviewed for this study. Among these subjects, 118 underwent SWE before US-guided FNA and CNB for thyroid nodules. According to the American [37] and Korean [38] management guidelines for patients with thyroid nodules, the FNA and CNB criteria for thyroid nodules were as follows: (1) a nodule has one of the finding for malignancy, such as microcalcifications, hypoechogenicity, irregular margins, or a taller-than-wide shape on US $>1.0 \mathrm{~cm}$ in diameter; (2) a nodule has indeterminate findings on US $>1.5 \mathrm{~cm}$ in diameter. To avoid artifacts by SWE, thyroid nodules with poor shear wave mapping $(n=9)$ or thyroid nodules including macrocalcifications $(n=2)$ and in the isthmic/paraisth- 
mic areas due to the interference produced by the tracheal cartilage $(n=8)$ were excluded. Thirty-eight thyroid nodules were also excluded because they were characterized, based on the CNB pathology, as papillary thyroid carcinoma $(n=19)$, chronic lymphocytic thyroiditis $(n=12)$, subacute thyroiditis $(n=3)$, or insufficiency $(n=4)$. Ultimately, the data from $42 \mathrm{NH}$ and $19 \mathrm{FN}$ from 61 patients were included in this study.

\section{Ultrasound-fine-needle aspiration and ultrasound- core-needle biopsy procedures}

During US, the patients were positioned with their neck extended. US was performed using an iU22 US with a 5- to $12-\mathrm{MHz}$ linear probe (Philips Healthcare, Bothell, WA, USA), a LOGIQ E9 system with a 6- to $15-\mathrm{MHz}$ linear array transducer (GE Healthcare, Milwaukee, WI, USA), and the Aixplorer US system with a frequency range of 15-4 MHz linear probe (SuperSonic Imagine, Aix-en-Provence, France). Each thyroid nodule was scanned in the longitudinal and transverse planes.

US-FNA procedures were performed under US guidance using 21- to 23-gauge needles attached to a $10-\mathrm{mL}$ syringe. Using a free hand technique, the needle tip was placed inside the targeted nodule. Liquid-based preparations (ThinPrep; Cytyc Co., Boxborough, MA, USA) were made, and cellblocks were made selectively. After FNA, every patient was observed with compression of the puncture site for 10 minutes.

US-CNB procedures were performed under local anesthesia with $1 \%$ lidocaine and US guidance using a disposable 18-guage, double-action spring-activated needle (TSK Ace-cut; Create Medic, Yokohama, Japan). Using a freehand technique, the tip of the biopsy needle was manually advanced to the margin of the nodule, and the stylet and cutting cannula of the needle were sequentially fired. The procedure was continuously monitored using US. The number of tissue cores obtained by $\mathrm{CNB}$ was in the range 1-3. All biopsy specimens were immediately fixed in $10 \%$ neutral buffered formalin solution. After CNB, every patients was observed with local compression of the biopsy site for 20-30 minutes.

\section{Imaging analysis}

US features of each thyroid nodules were described according to the internal contents, echogenicity, shape, margin, calcifications, central vascularity, and peripheral halo. Internal contents were classified as solid (solid component more than 90\%) and partially cystic (solid component less than 90\%). Echogenicity was divided into hypoechoic (nodules showing hypoechogenicity compared to the adjacent normal thyroid parenchyma) and hyper or isoechoic (nodules showing hyperechogenicity or isoechogenicity compared with the adjacent normal thyroid parenchyma). Shape was defined as parallel or non-parallel orientation (greater in the anteroposterior dimension than the transverse dimension). Margin was categorized as circumscribed or irregular (non-circumscribed).

For the SWE of thyroid, Aixplorer US system was used. After the gray-scale US, the system was changed to the SWE to use the same probe to perform SWE. Gray-scale US and SWE images appeared simultaneously on two panels. For placement of region of interest (ROI), Q-Box Trace program was applied which allows the user to draw the manual free-hand tracing of the margin of the nodule on B-mode scan which is overlaid on the color map of twodimensional-SWE (Fig. 1). The software automatically calculated shear elasticity indices in ROI as mean ( $\left.\mathrm{E}_{\text {Mean }}\right)$, minimum ( $\left.\mathrm{E}_{\mathrm{Min}}\right)$, maximum $\left(\mathrm{E}_{\mathrm{Max}}\right)$, and standard deviation $\left(\mathrm{E}_{\mathrm{SD}}\right)$ in $\mathrm{kPa}$. The color map of the tissue stiffness was coded ranged from dark blue (lowest stiffness; less than $36 \mathrm{kPa})$, light blue $(36-72 \mathrm{kPa})$, green, and yellow to red (more than $180 \mathrm{kPa}$ ).

High elasticity index (EI) area was defined as areas showing EI more than $36 \mathrm{kPa}$ (color coded from the light blue), and percent of high EI areas was calculated dividing the high EI area by the total area of the nodule. The patterns of high EI area were classified as marginal type (high EI areas are restricted in the outer $1 / 3$ of the nodule) and traversing type (high EI area approaching further to the center of the nodule within inner $2 / 3$ of the nodule) according to the patterns of high EI area.

\section{Pathologic analysis}

According to the Bethesda System for Reporting Thyroid Cytopathology [19], FNA cytology were divided into the following categories: I (nondiagnostic), II (benign), III (AUS/FLUS), IV (FN/ SFN), V (SM), and VI (malignant).

Diagnostic categories of thyroid CNB were divided according to the criteria reported by the Korean Endocrine Pathology study group [39]: category I (nondiagnostic), category II (benign lesion including benign follicular nodule, $\mathrm{NH}$ ), category IIIA (indeterminate follicular lesions with nuclear atypia), category IIIB (indeterminate follicular lesion with architectural atypia including microfollicular, solid, trabecular follicular lesion and Hürthle cell proliferative lesion lacking a fibrous capsule), category IV (FN/ SFN showing category IIIB lesion with a fibrous capsule), category 

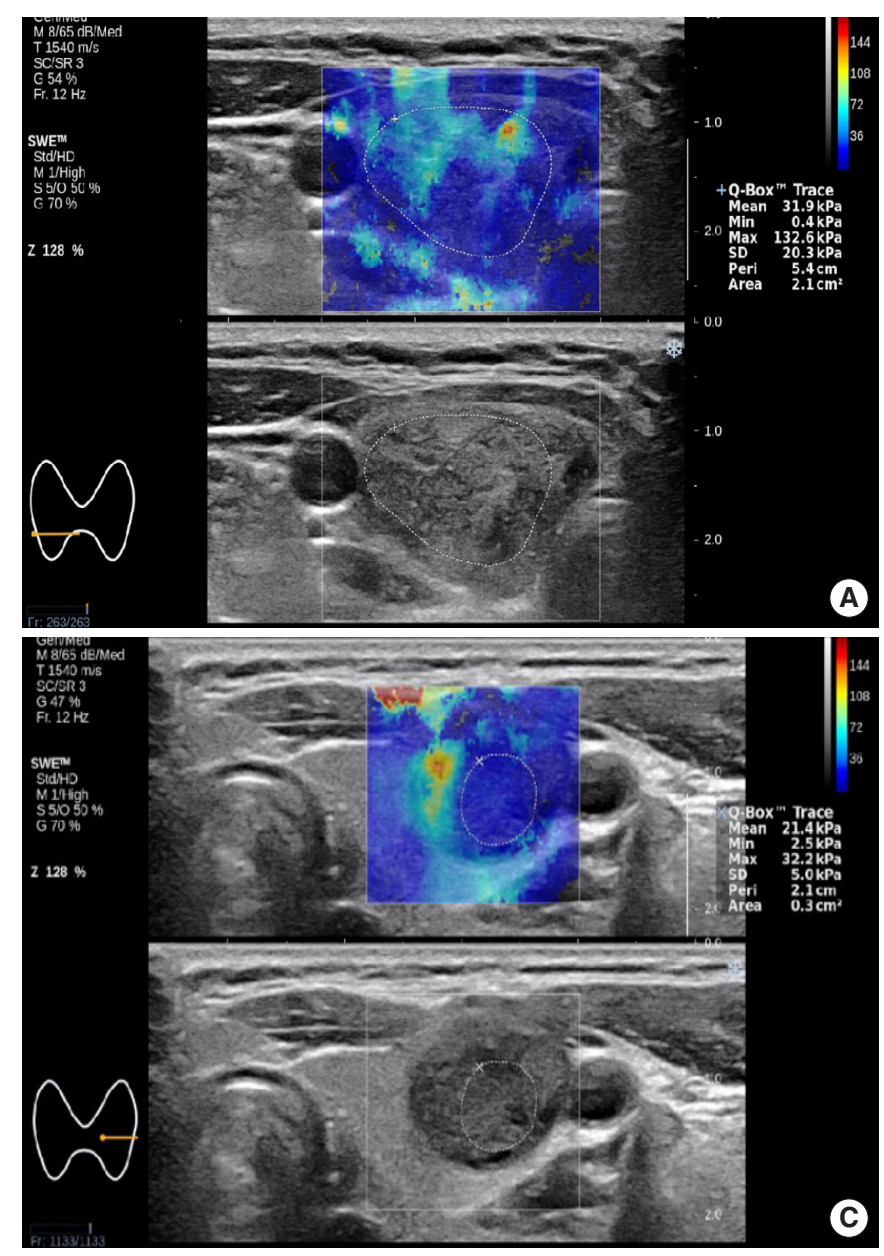

V (SM), and category VI (malignant). Endocrine pathologist (IH Choi) reviewed all CNB slides and CNB with category II is grouped as suggestive of $\mathrm{NH}$ and $\mathrm{CNB}$ with category IIIB and IV are grouped as suggestive of FN. Surgical histopathology was diagnosed according to the World Health Organization classification [5].

\section{Statistical analysis}

The Patient' ages at diagnosis, tumor sizes, tumor volumes, and elasticity values of the thyroid nodules are expressed as median (25th, 75th percentile), and differences between groups were compared using the Mann-Whitney U-test. Group comparisons of categorical variables were performed using the $\chi^{2}$ test or, for small cell values, Fisher's exact test. Results of categorical data area summarized using frequencies and percent values. We evaluated the sensitivity and specificity of the EI values to predict FN using a receiver-operating-characteristic (ROC) curve analysis, estimating the area under the curve with $95 \%$ confidence intervals. All statis-

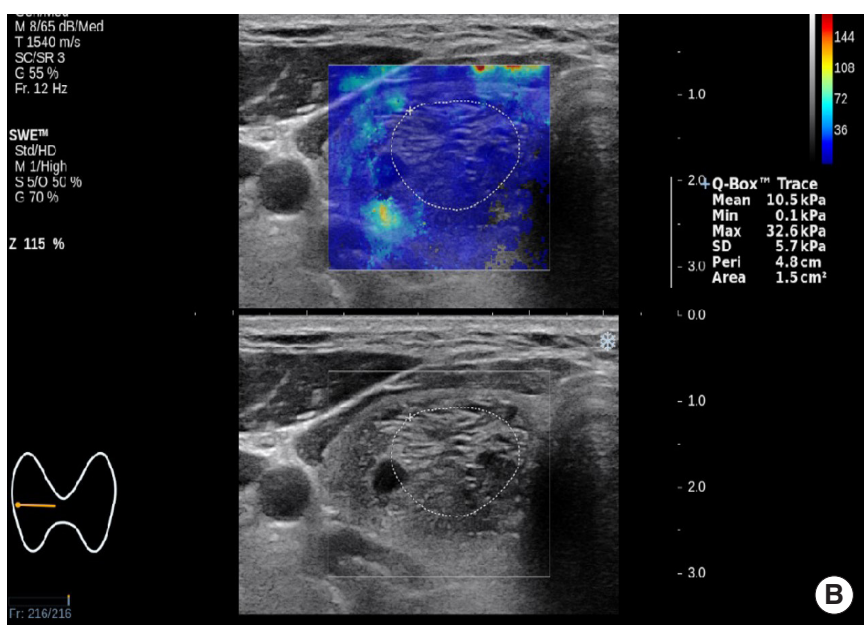

Fig. 1. SWE (upper image) and gray-scale ultrasound (lower image) in three patients. (A) SWE in a 46-year-old woman (case no. 4 in Table 6) with a nodular hyperplasia demonstrates markedly increased elasticity indices ( $E_{\text {Max }} 132.6$ kPa; $E_{\text {Mean }} 31.9 \mathrm{kPa}$ ) with traversing pattern of high elasticity index (>36 kPa) area traversing further than $1 / 3$ of the transverse diameter toward the center from the margin of the nodule. (B) SWE in a 58-year-old man (case no. 7 in Table 6) with a follicular adenoma shows diffusely low elasticity indices ( $E_{\operatorname{Max}} 32.6 \mathrm{kPa}$; $E_{\text {Mean }} 10.5 \mathrm{kPa}$ ). (C) SWE in a 40-year-old woman (case no. 10 in Table 6) with a follicular thyroid carcinoma demonstrates low elasticity indices ( $\mathrm{E}_{\mathrm{Max}} 32.2 \mathrm{kPa}$; $E_{\text {Mean }} 21.4 \mathrm{kPa}$ ) in central portion of the thyroid nodule with marginal pattern of high elasticity index ( $>36 \mathrm{kPa}$ ) area residing less than $1 / 3$ of the transverse diameter toward the center from the margin of the nodule, and marginal high elasticity was revealed to be due to thick fibrous capsule and not interstitial fibrosis on surgical histopathology. SWE, shear wave elastography; $\mathrm{E}_{\mathrm{Max}}$ maximum elasticity; $E_{\text {Mean, }}$ mean elasticity.

tical analyses were performed using the IBM SPSS Statistics ver. 25.0 software package (IBM Corp., Armonk, NY, USA) and P-value less than 0.05 was considered statistically significant.

\section{Ethics statement}

The present study protocol was reviewed and approved by the Institutional Review Board of Soonchunhyang University Hospital (IRB approval no., 2018-11-020). The requirement for informed consent for this study was waived by the institutional review board because this study only accessed the database for analytic purposes and was devoid of personal identifying information.

\section{RESULTS}

\section{Diagnostic accuracy of preoperative fine-needle aspiration and core-needle biopsy to detect follicular neoplasm compared with surgical pathology}

Among 141 patients who had surgical pathology results with 
Yoo $\mathrm{MH}$, et al. • Shear Elastography of Follicular Neoplasm

Table 1. Diagnostic accuracy of preoperative FNA to detect FN compared with surgical pathology ( $N=109)$

\begin{tabular}{|c|c|c|c|}
\hline \multirow{2}{*}{ FNA } & \multicolumn{2}{|c|}{ Surgical pathology } & \\
\hline & $\mathrm{NH}(\mathrm{n}=58)$ & $\mathrm{FN}(\mathrm{n}=51)$ & \\
\hline Benign $(n=67)$ & 39 (39 benign) & 28 (21 FA, 7 FTC) & \multirow{2}{*}{$\begin{array}{l}\text { Sensitivity }=45 \% \text {, specificity }=67 \%, \text { PPV }=55 \% \text {, } \\
\quad N P V=58 \% \text {, accuracy }=57 \%\end{array}$} \\
\hline $\mathrm{FN}(\mathrm{n}=42)$ & 19 (6 AUS/FLUS, 11 FN/SFN, 2 SM) & 23 (15FA, 8FTC) & \\
\hline
\end{tabular}

FNA, fine-needle aspiration; FN, follicular neoplasm; NH, nodular hyperplasia; FA, follicular adenoma; FTC, follicular thyroid carcinoma; AUS/FLUS, atypia of undetermined significance/follicular lesion of undetermined significance; FN/SFN, follicular neoplasm/suspicious for follicular neoplasm; SM, suspicious for malignancy; PPV, positive predictive value; NPV, negative predictive value.

Table 2. Diagnostic accuracy of preoperative CNB to detect FN compared with surgical pathology ( $N=56)$

\begin{tabular}{lccc}
\hline \multirow{2}{*}{ CNB } & \multicolumn{3}{c}{ Surgical pathology } \\
\cline { 2 - 3 } & $\mathrm{NH}(\mathrm{n}=23)$ & $\mathrm{FN}(\mathrm{n}=33)$ & \\
\hline $\mathrm{NH}(\mathrm{n}=23)$ & $17(17 \mathrm{NH})$ & $6(5 \mathrm{FA}, 1 \mathrm{FTC})$ & Sensitivity $=82 \%$, specificity $=74 \%, \mathrm{PPV}=82 \%$, \\
$\mathrm{FN}(\mathrm{n}=33)$ & $6(6 \mathrm{NH})$ & $27(17 \mathrm{FA}, 10 \mathrm{FTC})$ & $\mathrm{NPV}=74 \%$, accuracy $=79 \%$ \\
\hline
\end{tabular}

FNA, fine-needle aspiration; FN, follicular neoplasm; NH, nodular hyperplasia; FA, follicular adenoma; FTC, follicular thyroid carcinoma; AUS/FLUS, atypia of undetermined significance/follicular lesion of undetermined significance; FN/SFN, follicular neoplasm/suspicious for follicular neoplasm; SM, suspicious for malignancy; PPV, positive predictive value; NPV, negative predictive value.

Table 3. Surgical pathology of nodules with discordant FNA and CNB results

\begin{tabular}{lll}
\hline FNA & \multicolumn{1}{c}{ Concurrent CNB } & \multicolumn{1}{c}{ Surgical pathology } \\
\hline Benign $(n=17)$ & Follicular neoplasm $(n=17)$ & Nodular hyperplasia $(n=2)$ \\
& & Follicular adenoma $(n=9)$ \\
& & Follicular thyroid cancer $(n=6)$ \\
AUS/FLUS $(n=2)$ & Nodular hyperplasia $(n=2)$ & Nodular hyperplasia $(n=2)$ \\
FN/SFN $(n=3)$ & Nodular hyperplasia $(n=3)$ & Nodular hyperplasia $(n=3)$ \\
SM $(n=1)$ & Nodular hyperplasia $(n=1)$ & Follicular adenoma $(n=1)$ \\
\hline
\end{tabular}

FNA, fine-needle aspiration; CNB, core-needle biopsy; AUS/FLUS, atypia of undetermined significance/follicular lesion of undetermined significance; FN/SFN, follicular neoplasm/suspicious for follicular neoplasm; SM, suspicious for malignancy.

NH, FA, and FTC between January 2012 and December 2017, 122 (87\%) were performed US-guided FNA and 68 (48\%) underwent US-guided CNB.

Except for the 13 nodules that yielded nondiagnostic results on FNA, the diagnostic accuracy the US-guided FNA to detect FN compared with surgical pathology was $57 \%$ and the results are summarized in Table 1. Except for the 12 nodules that yielded insufficient results on CNB, Table 2 shows the diagnostic accuracy of the US-guided CNB to detect FN compared with surgical pathology was 79\%. CNB showed higher diagnostic accuracy than FNA (79\% versus 57\%). Twenty-three patients showed discordant FNA and CNB results, and the diagnosis and surgical pathology for the patients are presented in Table 3. Among 17 discordant patients with benign by FNA and FN by CNB, 15 patients were revealed as FN (nine FA and six FTC), suggesting better diagnostic accuracy to detect FN by CNB than FNA.
Table 4. Comparison of baseline characteristics between NH and FN ( $\mathrm{N}=61$ )

\begin{tabular}{|c|c|c|c|}
\hline Characteristic & $\mathrm{NH}(\mathrm{n}=42)$ & $\mathrm{FN}(\mathrm{n}=19)$ & P-value \\
\hline Female & $35(83)$ & $13(68)$ & $0.188^{a)}$ \\
\hline Age (yr) & $57(48,67)$ & $58(43,63)$ & $0.602^{b)}$ \\
\hline Solid/partially cystic & $22(52) / 20(48)$ & $10(53) / 9(47)$ & $0.986^{\mathrm{a})}$ \\
\hline Hypoechogenicity & $6(14)$ & $8(42)$ & $0.017^{\mathrm{a}}$ \\
\hline Non-parallel orientation & $1(2)$ & $1(5)$ & $0.530^{\mathrm{al}}$ \\
\hline Irregular margin & $16(38)$ & $3(16)$ & $0.135^{\mathrm{a})}$ \\
\hline Calcification & $8(19)$ & $6(32)$ & $0.281^{\mathrm{al}}$ \\
\hline Central vascularity & $19(45)$ & $10(53)$ & $0.592^{\mathrm{a})}$ \\
\hline Peripheral halo & $15(36)$ & $12(63)$ & $0.046^{\mathrm{a})}$ \\
\hline Tumor size (cm) & $2.1(1.6,2.5)$ & $2.2(1.5,3.0)$ & $0.901^{\mathrm{bl}}$ \\
\hline Tumor size $\geq 2 \mathrm{~cm}$ & $22(52)$ & $11(58)$ & $0.689^{a)}$ \\
\hline Tumor volume (mL) & $1.6(1.0,4.4)$ & $2.7(1.0,6.5)$ & $0.575^{b /}$ \\
\hline \multicolumn{4}{|l|}{ Elasticity indices (kPa) } \\
\hline$E_{\text {Mean }}$ & $28.9(24.3,37.2)$ & $17.2(14.1,21.0)$ & $<0.001^{\text {b) }}$ \\
\hline$E_{\text {Min }}$ & $9.4(2.2,15.2)$ & $3.6(1.8,10.1)$ & $0.135^{b)}$ \\
\hline $\mathrm{E}_{\operatorname{Max}}$ & $56.2(46.4,74.9)$ & $31.5(30.0,40.6)$ & $<0.001^{\text {bl }}$ \\
\hline $\mathrm{EsD}_{\mathrm{SD}}$ & $9.0(7.1,13.2)$ & $5.7(4.5,6.2)$ & $<0.001^{\mathrm{bl}}$ \\
\hline High El area (\%) & $36(28,61)$ & $0(0,0)$ & $<0.001^{\text {bl }}$ \\
\hline
\end{tabular}

Values are presented as number (\%) or median (25th, 75th percentiles), as appropriate.

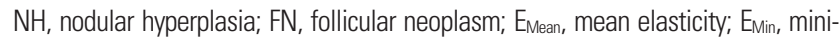
mum elasticity; $E_{M a x}$, maximum elasticity; $E_{s D}$, one standard deviation of elastographic values; El, elasticity index.

Statistical significance was determined by the ${ }^{a} \chi^{2}$ test or ${ }^{b}$ the Mann-Whitney Utest.

\section{Comparison of baseline characteristics between nodular hyperplasia and follicular neoplasm}

We compared the baseline characteristics of the 61 patients with $\mathrm{NH}$ and FN who were performed SWE and US-guided CNB from 
August 2016 through May 2018 (Table 4). Gray-scale US features of hypoechogenicity $(\mathrm{P}=0.017)$ and peripheral halo $(\mathrm{P}=0.046)$ were significantly more frequently found in $\mathrm{FN}$ than $\mathrm{NH}$. FN showed lower EI values than $\mathrm{NH}$, which were statistically significant for $\mathrm{E}_{\text {Mean }}(\mathrm{P}<0.001), \mathrm{E}_{\mathrm{Max}}(\mathrm{P}<0.001), \mathrm{E}_{\mathrm{SD}}(\mathrm{P}<0.001)$, and high EI area percent on SWE $(\mathrm{P}<0.001)$ (Fig. 2). There were no significant differences between the groups with respect to gender, age at diagnosis, gray-scale US features except for hypoechogenicity and peripheral halo, tumor size, tumor volume, or $\mathrm{E}_{\mathrm{Min}}$.

\section{Diagnostic accuracy of elasticity indices to detect follicular neoplasm}

The ROC analysis and diagnostic accuracy of EI for discrimination between FN and NH in CNB are presented in Fig. 3 and Table 5. A $\mathrm{E}_{\mathrm{Max}}$ level of $42.1 \mathrm{kPa}$ was the optimal cut-off value, giving a sensitivity of $95 \%$, a specificity of $90 \%$, a negative predictive value of $97 \%$, and a diagnostic accuracy of 92\%. (Fig. 3A, Table 5). A $\mathrm{E}_{\text {Mean }}$ level of $23.5 \mathrm{kPa}$ was the optimal cut-off value, providing a sensitivity of $95 \%$, a specificity of $79 \%$, a negative predictive value of $97 \%$, and a diagnostic accuracy of $84 \%$ (Fig. 3B, Table 5). We further explored diagnostic accuracy of EI according to pattern of high EI area (Table 5). Among 20 nodules with marginal pattern of high EI area, 17 (85\%) were FN and 3 (15\%) were found to be $\mathrm{NH}$ in CNB. Of 41 nodules with traversing pattern of high EI area, 39 (95\%) were $\mathrm{NH}$, whereas 2 (5\%) were FN resulting sensitivity, specificity, and diagnostic accuracy of marginal pattern of high EI area to predict $\mathrm{FN}$ as $89 \%, 93 \%$, and $92 \%$, respectively.

\section{Correlation between fine-needle aspiration, core- needle biopsy, and elasticity indices with surgical histopathology}

Among 61 nodules, 13 thyroid nodules from 13 patients were surgically resected (Table 6). On surgical histopathology, five were diagnosed as NH, four as FA, two as FTC, and two as follicular variant of PTC on surgical histopathology.

Except for the two nodules that yielded insufficient results by FNA with surgical pathology, six cases (55\%) revealed discordant results with FNA; one of $\mathrm{NH}$ was misdiagnosed as FN/SFN, and three FA and two FTC were misdiagnosed as benign by FNA.

On preoperative $\mathrm{CNB}$, three FA and one FTC were misdiagnosed as benign. Diagnostic accuracy of CNB showed 67\% (8/12) when excluding one nodule that yielded a nondiagnostic result.
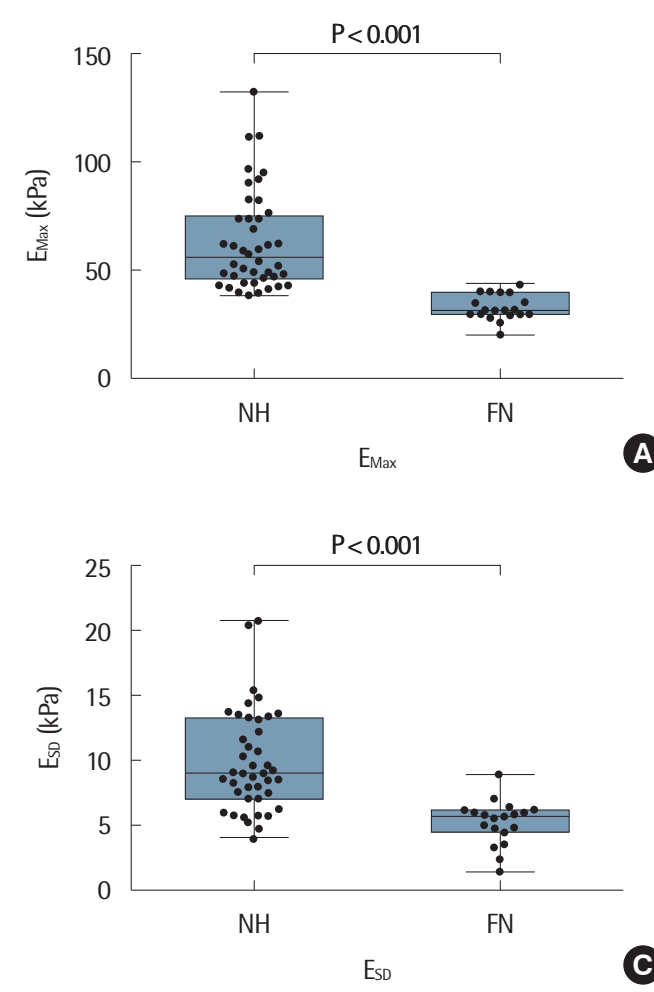
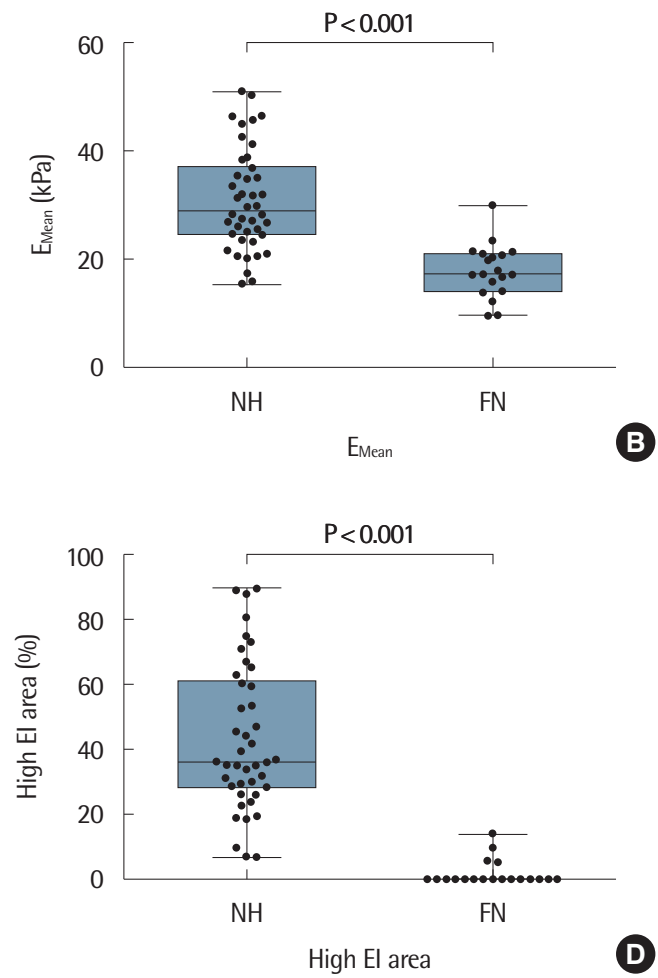

Fig. 2. (A-D) Box-and-whisker plots of $E_{M a x}, E_{M e a n,} E_{S D}$, and high El area (\%) for $N H(n=42)$ and $F N(n=19)$. NH, nodular hyperplasia; $F N$, follicular neoplasm; $E_{M a x}$, maximum elasticity; $E_{\text {Mean, }}$ mean elasticity; $E_{S D}$, one standard deviation of elastographic values; El, elasticity index. 

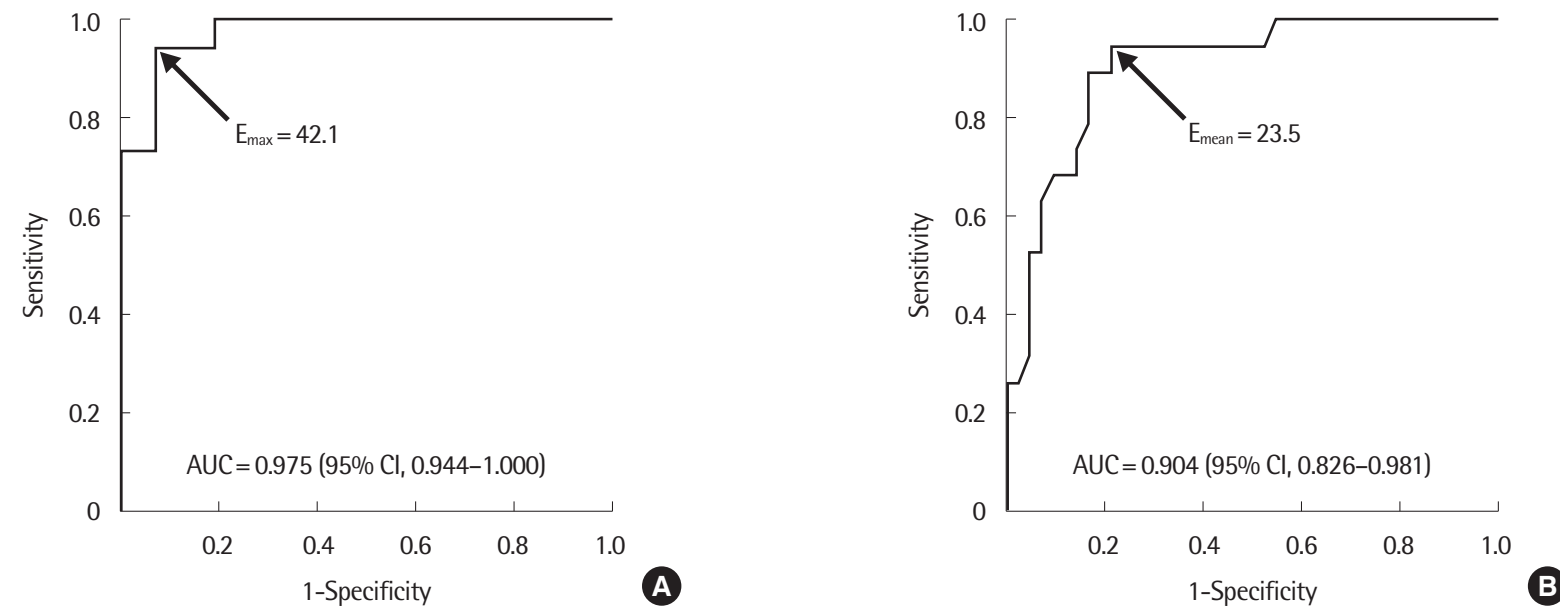

Fig. 3. Receiver operating characteristic curves to differentiate follicular neoplasm form nodular hyperplasia. (A) EMax. (B) Emean. AUC, area under the curve; $\mathrm{Cl}$, confidence interval; $E_{M a x}$ maximum elasticity; $E_{M e a n}$, mean elasticity.

Table 5. Diagnostic accuracy of elasticity indices to detect FN ( $\mathrm{N}=61)$

\begin{tabular}{lcccc}
\hline \multirow{2}{*}{ Variable } & \multicolumn{1}{c}{ Category } & \multicolumn{2}{c}{ Core-needle biopsy } & \\
\cline { 2 - 3 } & & $\mathrm{NH}(\mathrm{n}=42)$ & $\mathrm{FN}(\mathrm{n}=19)$ & \\
\hline EMax & $<42.1 \mathrm{kPa}(\mathrm{n}=22)$ & 4 & 18 & Sensitivity $=95 \%$, specificity $=90 \%, \mathrm{PPV}=82 \%, \mathrm{NPV}=97 \%$, \\
& $\geq 42.1 \mathrm{kPa}(\mathrm{n}=39)$ & 38 & 1 & accuracy $=92 \%$ \\
EMean & $<23.5 \mathrm{kPa}(\mathrm{n}=27)$ & 9 & 18 & Sensitivity $=95 \%$, specificity $=79 \%, \mathrm{PPV}=67 \%, \mathrm{NPV}=97 \%$, \\
& $\geq 23.5 \mathrm{kPa}(\mathrm{n}=34)$ & 33 & 1 & accuracy $=84 \%$ \\
High El area pattern & Marginal $(\mathrm{n}=20)$ & 3 & 17 & Sensitivity $=89 \%$, specificity $=93 \%, \mathrm{PPV}=85 \%, \mathrm{NPV}=95 \%$, \\
& Traversing $(\mathrm{n}=41)$ & 39 & 2 & accuracy $=92 \%$ \\
\hline
\end{tabular}

FN, follicular neoplasm; NH, nodular hyperplasia; $E_{\text {Max }}$, maximum elasticity; $E_{\text {Mean, }}$ mean elasticity; El, elasticity index; PPV, positive predictive value; NPV, negative predictive value.

Table 6. Correlation between FNA, CNB, and elasticity indices with surgical histopathology

\begin{tabular}{|c|c|c|c|c|c|c|}
\hline \multirow{2}{*}{ Case } & \multirow{2}{*}{ Surgical pathology } & \multirow{2}{*}{ FNA } & \multirow{2}{*}{ Concurrent CNB } & \multicolumn{3}{|c|}{ Elasticity index } \\
\hline & & & & $\mathrm{E}_{\operatorname{Max}}(\mathrm{kPa})$ & $E_{\text {Mean }}(\mathrm{kPa})$ & $M / T$ \\
\hline 1 & $\mathrm{NH}$ & Benign & $\mathrm{NH}$ & 41.8 & 25.0 & $T$ \\
\hline 2 & $\mathrm{NH}$ & Benign & $\mathrm{NH}$ & 48.9 & 29.5 & $M$ \\
\hline 3 & $\mathrm{NH}$ & FN/SFN & Insufficient & 47.8 & 24.6 & $\mathrm{~T}$ \\
\hline 4 & $\mathrm{NH}$ & Insufficient & $\mathrm{NH}$ & 132.6 & 31.9 & $\mathrm{~T}$ \\
\hline 5 & $\mathrm{NH}$ & Insufficient & $\mathrm{NH}$ & 76.6 & 23.2 & $\mathrm{~T}$ \\
\hline 6 & FA & Benign & $\mathrm{NH}$ & 40.7 & 14.0 & M \\
\hline 7 & FA & Benign & $\mathrm{NH}$ & 32.6 & 10.5 & M \\
\hline 8 & FA & Benign & $\mathrm{NH}$ & 20.8 & 16.8 & $M$ \\
\hline 9 & FA & FN/SFN & FN & 32.0 & 17.2 & $M$ \\
\hline 10 & FTC & Benign & $\mathrm{NH}$ & 32.2 & 21.4 & $M$ \\
\hline 11 & FTC & Benign & FN & 30.0 & 9.7 & M \\
\hline 12 & Follicular variant of PTC & FN/SFN & FN & 43.9 & 29.8 & $M$ \\
\hline 13 & Follicular variant of PTC & SM & FN & 35.8 & 14.1 & M \\
\hline \multicolumn{2}{|c|}{ Diagnostic accuracy (\%) } & 45 & 67 & 85 & 85 & 92 \\
\hline \multicolumn{2}{|c|}{ No. of concordantal/total (insufficient) } & $5 / 11(2)$ & $8 / 12(1)$ & $11 / 13(0)$ & $11 / 13(0)$ & $12 / 13(0)$ \\
\hline
\end{tabular}

FNA, fine-needle aspiration; CNB, core-needle biopsy; $\mathrm{E}_{\mathrm{Max}}$, maximum elasticity; $\mathrm{E}_{\mathrm{Mean},}$ mean elasticity; $\mathrm{T}$, traversing pattern of high elasticity index area; $\mathrm{M}$, marginal pattern; NH, nodular hyperplasia; FN/SFN, follicular neoplasm/suspicious for follicular neoplasm; FA, follicular adenoma; FTC, follicular thyroid carcinoma; FN, follicular neoplasm; PTC, papillary thyroid cancer; SM, suspicious for malignancy.

${ }^{\mathrm{a}} \mathrm{E}_{\mathrm{Max}}<42.1 \mathrm{kPa}$, $\mathrm{E}_{\text {Mean }}<23.5 \mathrm{kPa}$, and marginal pattern of high elasticity index ( $>36 \mathrm{kPa}$ ) area were considered as concordant with FN. 
$\mathrm{E}_{\mathrm{Max}}$ values were more than $42.1 \mathrm{kPa}$ in four of five $\mathrm{NH}$ and less than $42.1 \mathrm{kPa}$ in all FA and FTC. For two cases of follicular variant PTC, one showed $\mathrm{E}_{\mathrm{Max}}$ more than $42.1 \mathrm{kPa}$, and the other showed $\mathrm{E}_{\mathrm{Max}}$ less than $42.1 \mathrm{kPa}$. $\mathrm{E}_{\text {Mean }}$ values were more than $23.5 \mathrm{kPa}$ in four of five $\mathrm{NH}$ and less than $23.5 \mathrm{kPa}$ in all FA and FTC. For two cases of follicular variant PTC, one showed $\mathrm{E}_{\text {Mean }}$ more than 23.5 $\mathrm{kPa}$, and the other showed $\mathrm{E}_{\mathrm{Mean}}$ less than $23.5 \mathrm{kPa}$. Diagnostic accuracy of $\mathrm{E}_{\mathrm{Max}}$ and $\mathrm{E}_{\mathrm{Mean}}$ showed 85\% (11/13) and 85\% (11/13), respectively. For pattern of high EI area, four of five $\mathrm{NH}$ showed a traversing pattern. All FA, FTC, and follicular variant PTC showed a marginal pattern. Diagnostic accuracy of pattern of high EI area was $92 \%(12 / 13)$.

\section{DISCUSSION}

Our study showed retrospective analysis of surgical pathology of 141 follicular lesion, 54\% (77/141) was NH and 53\% (58/109) by FNA group and $41 \%(23 / 56)$ by $\mathrm{CNB}$ group revealed as $\mathrm{NH}$ on surgery. $\mathrm{NH}$ accounts for $30 \%-50 \%$ of the benign diagnostic surgery $[13,20,40,41]$. Exclusion and preoperative detection of $\mathrm{NH}$ may reduce diagnostic surgery for benign thyroid nodules.

Differential diagnosis of follicular patterned thyroid nodules is difficult on FNA which does not show the architectural structure of the nodules, including the presence of the complete formation of the capsule nor presence of heterogeneous hyperplastic and involutionary or degenerative changes inside $[4,34,35]$. CNB can show possible formation of intact capsule and the presence of heterogeneity of the follicular proliferation and degenerative change, but not always possible depending on the cutting site of CNB. In case when $\mathrm{CNB}$ was obtained in the microfollicular hyperplastic site of $\mathrm{NH}$ [35], CNB may suggest the possibility of FN. When CNB does not include capsule of the FN with macrofollicular pattern, it may be similar to the part of NH. So the diagnostic accuracy of $\mathrm{CNB}$ of follicular patterned lesion compared with surgical histopathology may not be $100 \%$. We reviewed the histopathology of the surgically resected specimen of follicular patterned lesions and compared the preoperative results of FNA and CNB with surgical histopathology. Our study showed $\mathrm{CNB}$ was more effective in the diagnosis of FN than FNA. Chen et al. [32] reported the accuracies of preoperative CNB and FNA to predict FN were $75 \%$ and $56 \%$, respectively, with positive predictive values of $65 \%$ and $46 \%$, compatible with our results. Min et al. [31] investigated the thyroid nodules which showed $\mathrm{FN}$ in preoperative $\mathrm{CNB}$ results and reported diagnostic accuracies of preoperative CNB and FNA to diagnose FN postoperatively were $88 \%$ and $74 \%$, respectively, higher than our study probably due to different way in the inclusion of the study subjects. Our data showed major difference of diagnostic accuracies between CNB and FNA was caused by the less detectability of FN by FNA and misdiagnosed as category II (Table 4). Several reports suggested careful decision based on multiple disciplines besides FNA may be needed for the management of the nodules with follicular lesion in FNA considering risk factors for FTC including large in size, male sex, old age and growing nodules $[13,22,42]$.

According to our results, SWE may be useful to pick up FN among follicular lesions by FNA or CNB. Our study showed EI ( $E_{M a x}, E_{M e a n}$, and $\left.E_{S D}\right)$ of $F N$ was significantly lower in FN than $\mathrm{NH}$. Diagnostic performance of marginal pattern of high EI area (more than $36 \mathrm{kPa}$ ) to diagnose FN showed the sensitively, specificity, and diagnostic accuracy was $89 \%, 93 \%$, and $92 \%$, respectively.

When we analyzed 13 patients with follicular lesion who underwent surgery, diagnostic accuracy of FNA was $45 \%$ (5/11) to predict FN in follicular lesion and the diagnostic accuracy of CNB to predict FN in follicular lesion was $67 \%$ (8/12) compatible with our larger series (Tables 1, 2). The diagnostic accuracies of $\mathrm{E}_{\mathrm{Max}}, \mathrm{E}_{\mathrm{Mean}}$, and the pattern of SWE to predict FN in follicular lesion was $85 \%$, $85 \%$, and $92 \%$, respectively, compatible with our larger data diagnostic accuracies by CNB (Table 5). Samir et al. [43] studied 35 follicular patterned nodules with AUS/FLUS or SFN by FNA and benign nodules on surgical pathology (20 FAs and four Hürthle cell adenomas) showed lower $\mathrm{E}_{\mathrm{Mean}}$ than 11 malignant nodules (six follicular variant PTCs, three FTCs, one Hürthle cell carcinomas, and one differentiated thyroid carcinoma) and cut-off values of $22.3 \mathrm{kPa}$ showed sensitivity of $82 \%$ and specificity of $88 \%$. Our results showed in 13 nodules with surgical pathology, eight nodules revealed FN including four FAs (benign), four malignant nodules (two follicular variant PTCs and two FTCs) and one follicular variant PTC showed $\mathrm{E}_{\mathrm{Mean}}$ of $29.8 \mathrm{kPa}$, above $23.5 \mathrm{kPa}$ and another seven nodules showed $\mathrm{E}_{\text {Mean }}$ of below $23.5 \mathrm{kPa}$, suggesting in $\mathrm{FN}$ and follicular variant PTC may show elevated $\mathrm{E}_{\text {Mean. }}$. Our data suggested $\mathrm{EI}$ of SWE ( $\mathrm{E}_{\mathrm{Max}}$ and $\mathrm{E}_{\mathrm{Mean}}$ ) and pattern of high $\mathrm{EI}$ area showed high diagnostic accuracy to differentiate FN from $\mathrm{NH}$ in follicular lesion even more accurate than $\mathrm{CNB}$, probably due to the ability to evaluate the larger parenchyma of the nodule than focal small pieces of CNB of thyroid, as FibroScan has been useful 
in the diagnosis of liver cirrhosis.

If $\mathrm{NH}$ can be easily excluded preoperatively in nodules with follicular lesion by SWE, it will reduce the rate of diagnostic benign surgery about $30 \%-50 \%$, and increase the rate of malignancy up to two folds, because $\mathrm{NH}$ accounts for $30 \%-50 \%$ of benign diagnostic surgery. And when these SWE criteria will be combined with molecular tests, it will also increase the specificity of molecular tests by excluding the false positive results by $\mathrm{NH}$. It also will be useful to select FN in large numbers of nodules with category II benign follicular nodule by FNA to avoid missing FN, especially the risk of FTC. In our study, one patient of the surgically proven FTC was directed to diagnostic surgery for $\mathrm{E}_{\mathrm{Max}}$ less than $42.1 \mathrm{kPa}$ and the marginal pattern of high EI area was revealed as minimally invasive FTC.

In conclusion, novel diagnostic criteria of $\mathrm{E}_{\mathrm{Max}}$ less than $42.1 \mathrm{kPa}$ and marginal pattern of high EI area $(>36 \mathrm{kPa})$ can predict $\mathrm{FN}$ with high diagnostic accuracy. It will help to waive benign diagnostic surgery of $\mathrm{NH}$ in nodules with indeterminate cytology and also select FN in category II nodules to avoid the risk of FTC, especially in large nodules. Novel diagnostic criteria of SWE to differentiate FN from NH in follicular lesions will be useful with the advantage of noninvasiveness, no need of great skill, relatively low cost, and high accuracy as FibroScan has been useful in liver cirrhosis. Limitations of our study is evaluation with diagnostic standard of surgical histopathology or $\mathrm{CNB}$, for not all follicular lesion could be directed to surgery. The number of histopathologically confirmed cases after surgery is small (13 out of 61). Larger numbers of the data with surgical histopathology may be needed in the future.

\section{ACKNOWLEDGMENTS}

This work was supported by the Soonchunhyang University Research Fund.

\section{REFERENCES}

1. Mazzaferri EL. Management of a solitary thyroid nodule. N Engl J Med 1993;328:553-9.

2. Tan GH, Gharib H. Thyroid incidentalomas: management approaches to nonpalpable nodules discovered incidentally on thyroid imaging. Ann Intern Med 1997;126:226-31.

3. Bongiovanni M, Spitale A, Faquin WC, Mazzucchelli L, Baloch ZW. The Bethesda System for Reporting Thyroid Cytopathology: a meta-analysis. Acta Cytol 2012;56:333-9.
4. Kumar V, Abbas AK, Aster JC. Robbins and Cotran pathologic basis of disease. 9th ed. Philadelphia (PA): Saunders Elsevier; 2015.

5. Lloyd RV, Osamura RY, Kloppel G, Rosai J. WHO classification of tumours of endocrine organs (medicine). 4th ed. Lyon: International Agency for Research on Cancer; 2017.

6. Ali SZ, Cibas ES. The Bethesda System for Reporting Thyroid Cytopathology: definitions, criteria and explanatory notes. New York (NY): Springer; 2010.

7. Alexander EK. Approach to the patient with a cytologically indeterminate thyroid nodule. J Clin Endocrinol Metab 2008;93:4175-82.

8. Greaves TS, Olvera M, Florentine BD, Raza AS, Cobb CJ, Tsao-Wei DD, et al. Follicular lesions of thyroid: a 5-year fine-needle aspiration experience. Cancer 2000;90:335-41.

9. Maruta J, Hashimoto H, Suehisa Y, Yamashita H, Noguchi S, Aratake Y, et al. Improving the diagnostic accuracy of thyroid follicular neoplasms: cytological features in fine-needle aspiration cytology. Diagn Cytopathol 2011;39:28-34

10. Jeh SK, Jung SL, Kim BS, Lee YS. Evaluating the degree of conformity of papillary carcinoma and follicular carcinoma to the reported ultrasonographic findings of malignant thyroid tumor. Korean J Radiol 2007;8: 192-7.

11. Sillery JC, Reading CC, Charboneau JW, Henrichsen TL, Hay ID, Mandrekar JN. Thyroid follicular carcinoma: sonographic features of 50 cases. AJR Am J Roentgenol 2010;194:44-54.

12. Marhefka GD, McDivitt JD, Shakir KM, Drake AJ 3rd. Diagnosis of follicular neoplasm in thyroid nodules by fine needle aspiration cytology: does the result, benign vs. suspicious for a malignant process, in these nodules make a difference? Acta Cytol 2009;53:517-23.

13. Baloch ZW, Fleisher S, LiVolsi VA, Gupta PK. Diagnosis of "follicular neoplasm": a gray zone in thyroid fine-needle aspiration cytology. Diagn Cytopathol 2002;26:41-4

14. Yeh MW, Demircan O, Ituarte P, Clark OH. False-negative fine-needle aspiration cytology results delay treatment and adversely affect outcome in patients with thyroid carcinoma. Thyroid 2004;14:207-15.

15. Bohacek L, Milas M, Mitchell J, Siperstein A, Berber E. Diagnostic accuracy of surgeon-performed ultrasound-guided fine-needle aspiration of thyroid nodules. Ann Surg Oncol 2012;19:45-51.

16. Bahar G, Braslavsky D, Shpitzer T, Feinmesser R, Avidan S, Popovtzer A, et al. The cytological and clinical value of the thyroid "follicular lesion". Am J Otolaryngol 2003;24:217-20.

17. Carling T, Udelsman R. Follicular neoplasms of the thyroid: what to recommend. Thyroid 2005;15:583-7.

18. Yoon RG, Baek JH, Lee JH, Choi YJ, Hong MJ, Song DE, et al. Diagnosis of thyroid follicular neoplasm: fine-needle aspiration versus core-needle biopsy. Thyroid 2014;24:1612-7.

19. Cibas ES, Ali SZ. The 2017 Bethesda System for Reporting Thyroid Cytopathology. Thyroid 2017;27:1341-6.

20. Jo VY, Stelow EB, Dustin SM, Hanley KZ. Malignancy risk for fine-needle aspiration of thyroid lesions according to the Bethesda System for Reporting Thyroid Cytopathology. Am J Clin Pathol 2010;134:450-6.

21. Zeiger MA, Dackiw AP. Follicular thyroid lesions, elements that affect both diagnosis and prognosis. J Surg Oncol 2005;89:108-13.

22. Gulcelik NE, Gulcelik MA, Kuru B. Risk of malignancy in patients with follicular neoplasm: predictive value of clinical and ultrasonographic features. Arch Otolaryngol Head Neck Surg 2008;134:1312-5.

23. Yoon JH, Kim EK, Youk JH, Moon HJ, Kwak JY. Better understanding in the differentiation of thyroid follicular adenoma, follicular carcinoma, and follicular variant of papillary carcinoma: a retrospective study. Int J Endocrinol 2014;2014:321595. 
24. Nasrollah N, Trimboli P, Guidobaldi L, Cicciarella Modica DD, Ventura C, Ramacciato G, et al. Thin core biopsy should help to discriminate thyroid nodules cytologically classified as indeterminate: a new sampling technique. Endocrine 2013;43:659-65.

25. Alexander EK, Kennedy GC, Baloch ZW, Cibas ES, Chudova D, Diggans J, et al. Preoperative diagnosis of benign thyroid nodules with indeterminate cytology. N Engl J Med 2012;367:705-15.

26. Nikiforov YE. Role of molecular markers in thyroid nodule management: then and now. Endocr Pract 2017;23:979-88.

27. Taye A, Gurciullo D, Miles BA, Gupta A, Owen RP, Inabnet WB 3rd, et al. Clinical performance of a next-generation sequencing assay (ThyroSeq v2) in the evaluation of indeterminate thyroid nodules. Surgery 2018 163:97-103

28. Valderrabano P, Khazai L, Thompson ZJ, Leon ME, Otto KJ, HallangerJohnson JE, et al. Impact of oncogene panel results on surgical management of cytologically indeterminate thyroid nodules. Head Neck 2018;40: 1812-23.

29. Yang SE, Sullivan PS, Zhang J, Govind R, Levin MR, Rao JY, et al. Has Afirma gene expression classifier testing refined the indeterminate thyroid category in cytology? Cancer Cytopathol 2016;124:100-9.

30. Nikiforova MN, Mercurio S, Wald AI, Barbi de Moura M, Callenberg K, Santana-Santos L, et al. Analytical performance of the ThyroSeq v3 genomic classifier for cancer diagnosis in thyroid nodules. Cancer 2018; 124:1682-90.

31. Min HS, Kim JH, Ryoo I, Jung SL, Jung CK. The role of core needle biopsy in the preoperative diagnosis of follicular neoplasm of the thyroid. APMIS 2014;122:993-1000.

32. Chen BT, Jain AB, Dagis A, Chu P, Vora L, Maghami E, et al. Comparison of the efficacy and safety of ultrasound-guided core needle biopsy versus fine-needle aspiration for evaluating thyroid nodules. Endocr Pract 2015;21:128-35.

33. Trimboli P, Crescenzi A. Thyroid core needle biopsy: taking stock of the situation. Endocrine 2015;48:779-85.

34. DeMay RM. Follicular lesions of the thyroid: w(h)ither follicular carcino- ma? Am J Clin Pathol 2000;114:681-3.

35. Baloch ZW, Livolsi VA. Follicular-patterned lesions of the thyroid: the bane of the pathologist. Am J Clin Pathol 2002;117:143-50.

36. Barr RG, Ferraioli G, Palmeri ML, Goodman ZD, Garcia-Tsao G, Rubin J, et al. Elastography assessment of liver fibrosis: Society of Radiologists in Ultrasound consensus conference statement. Radiology 2015;276:84561 .

37. Haugen BR, Alexander EK, Bible KC, Doherty GM, Mandel SJ, Nikiforov YE, et al. 2015 American Thyroid Association management guidelines for adult patients with thyroid nodules and differentiated thyroid cancer: the American Thyroid Association Guidelines Task Force on Thyroid Nodules and Differentiated Thyroid Cancer. Thyroid 2016;26:1-133.

38. Yi KH, Park YJ, Koong SS, Kim JH, Na DG, Ryu JS, et al. Revised Korean Thyroid Association management guidelines for patients with thyroid nodules and thyroid cancer. Endocrinol Metab 2010;25:270-97.

39. Jung CK, Min HS, Park HJ, Song DE, Kim JH, Park SY, et al. Pathology reporting of thyroid core needle biopsy: a proposal of the Korean Endocrine Pathology Thyroid Core Needle Biopsy Study Group. J Pathol Transl Med 2015;49:288-99.

40. Schreiner AM, Yang GC. Adenomatoid nodules are the main cause for discrepant histology in 234 thyroid fine-needle aspirates reported as follicular neoplasm. Diagn Cytopathol 2012;40:375-9.

41. Ho AS, Sarti EE, Jain KS, Wang H, Nixon IJ, Shaha AR, et al. Malignancy rate in thyroid nodules classified as Bethesda category III (AUS/FLUS). Thyroid 2014;24:832-9.

42. Schlinkert RT, van Heerden JA, Goellner JR, Gharib H, Smith SL, Rosales $\mathrm{RF}$, et al. Factors that predict malignant thyroid lesions when fine-needle aspiration is "suspicious for follicular neoplasm". Mayo Clin Proc 1997;72: 913-6.

43. Samir AE, Dhyani M, Anvari A, Prescott J, Halpern EF, Faquin WC, et al. Shear-wave elastography for the preoperative risk stratification of follicular-patterned lesions of the thyroid: diagnostic accuracy and optimal measurement plane. Radiology 2015;277:565-73. 